\title{
Dramaturgas y censura en el último Franquismo: Carmen Resino y Ana Diosdado*
}

\section{Female Dramatists and Censorship during the Last Period of the Franco Regime: Carmen Resino and Ana Diosdado}

\author{
Diego Santos Sánchez \\ Humboldt-Universität zu Berlin \\ dsantos@post.harvard.edu
}

\begin{abstract}
RESUMEN
Partiendo de los expedientes censores, este trabajo aborda el modo en que la censura de los últimos años del Franquismo entendió y gestionó el teatro escrito por mujeres y el rol de la dramaturga en el mundo teatral. Ello se ilustrará a través de las dos autoras más representativas y populares de la década de los setenta: Carmen Resino y Ana Diosdado. El modo en que la censura conceptuó su labor será puesto en perspectiva y enlazado tanto con la situación de las autoras del primer Franquismo como con la génesis de la dramaturgia femenina de la democracia.
\end{abstract}

Palabras Clave: Teatro; mujer; censura; Carmen Resino; Ana Diosdado.

\begin{abstract}
Drawing on censorship files, this article studies how censorship tackled the theatre written by women and the role of the female playwright during the last years of the Franco regime. This will be illustrated through the two most representative and popular dramatists from the seventies: Carmen Resino and Ana Diosdado. The way their work was judged by the censors will be assessed and linked with the situation of earlier female authors from the Franco period as well as with the female theatre shaped during the post-Franco era.
\end{abstract}

Key words: Theatre; Woman; Censorship; Carmen Resino; Ana Diosdado.

* La idea de este artículo surgió tras mi primer contacto con los expedientes de censura citados en este trabajo, que tuvo lugar en el marco del proyecto «Theatre Censorship in Spain (1931-1985)», financiado por el Arts \& Humanities Research Council y con sede en Durham University (Reino Unido), mientras que toda la investigación bibliográfica y la confección del mismo se desarrollaron en la Humboldt-Universität zu Berlin gracias a un contrato de investigación de la Alexander von Humboldt-Stiftung (Alemania).

Copyright: (C) 2016 CSIC. Este es un artículo de acceso abierto distribuido bajo los términos de una licencia de uso y distribución Creative Commons Attribution (CC-by) España 3.0. 


\section{MUJER, TEATRO Y FRANQUISMO}

El Franquismo le otorgó a la mujer un papel en la sociedad que quedaba muy lejos del alcanzado durante la Segunda República, que había conquistado «un grado de independencia económica, legal y sexual mayor que nunca» (Scanlon, 1986: 320). Tras el desastre de la guerra, la dictadura invirtió la tendencia y contribuyó a través de sus políticas a convertir a la mujer en un ángel del hogar destinado a promover la natalidad (Roca i Girona, 1996: 233). La maternidad se convertía en el eje sobre el que giraría la concepción de lo femenino (Gallego Méndez, 1983: 161) y el estado, a través de instituciones como la Sección Femenina, consolidaba una visión de la mujer cuyo compromiso «para con la Patria [sic] consist[ía] en formar familias» (Primo de Rivera, s.f.: 28). Esta política de género redundó en un marcado detrimento del papel de la mujer en el ámbito de la producción cultural y especialmente en el del teatro.

El teatro, sometido a intereses que trascienden lo meramente cultural y literario, se ha descrito con frecuencia como un género especialmente hostil a la mujer, que habría rehuido del mundo eminentemente masculino de la crítica y la empresa teatrales para refugiarse en géneros más intimistas como la novela (Zaza, 2007: 3). Esta creencia generalizada ha comenzado a cuestionarse desde el discurso académico en los últimos años. Por un lado gracias a los estudios de autoras teatrales de la Edad de Plata y la Segunda República, en que el papel de la mujer fue más que destacable ${ }^{1}$; y, por otro, gracias a los estudios que, en una línea de compromiso con la memoria histórica, recuperan dramaturgias silenciadas por la dictadura, entre las que destacan algunas autoras exiliadas ${ }^{2}$. Ambas iniciativas han servido de antesala para los estudios específicos sobre las dramaturgas de los años de la dictadura. Porque, a pesar del contexto esbozado más arriba, hubo una serie de autoras que decidieron adentrarse por los senderos del mundo teatral ${ }^{3}$.

La crítica ha lamentado la poca atención que este fenómeno ha suscitado en el discurso académico (O’Connor, 1990a: 378; Aszyk, 1992: 45; Zaza, 2007: 1; Serrano, 2002: 88), pero lo cierto es que en los últimos años hemos asistido a una proliferación sin precedentes de trabajos que se ocupan de esta dramaturgia ${ }^{4}$. Se ha señalado, sin embargo, que las autoras del Franquismo «pa-

\footnotetext{
${ }^{1}$ Destaca en este sentido el trabajo de Pilar Nieva de la Paz (1993), al que hay que sumar estudios específicos sobre autoras como Halma Angélico o María Teresa León (Nieva de la Paz, 1992 y Aznar Soler, 1993, respectivamente).

${ }^{2}$ Los trabajos de Julio Checa Puerta (2009), Emilio Miró (1992), Eduardo Pérez-Rasilla (2003) o Francisca Vilches de Frutos (2010a y 2010b) recuperan las figuras de autoras como María Martínez Sierra, Concha Méndez, Luisa Carnés o María Teresa León, entre otras.

${ }^{3}$ Entre los listados que dan cuenta de los nombres de estas autoras destacan Serrano (2002) y Hormigón (1997).

${ }^{4}$ Entre la bibliografía destacan los trabajos de Patricia O’Connor (1987, 1988, 1990a, 1990b, 1992, 2007a, 2007b), Pilar Nieva de la Paz (2001, 2004, 2009a, 2009b), Francisca
} 
recían renegar de su identidad femenina, representando en sus obras los puntos de vista masculinos» y que crearon «intertextos patriarcales» en que, «como los hombres, han tendido a idealizar la maternidad, pintar de modo positivo a la mujer sumisa cuya principal meta es agradar y servir al hombre al tiempo que ponen en ridículo a la mujer independiente o intelectual» (O'Connor, 1987: 108). Fuese de modo consciente o inconsciente, lo cierto es que por lo general estas autoras adoptaron las actitudes, los prejuicios y el estilo del teatro dominante, escrito por hombres, como única vía para poder adentrarse en el mundo teatral. Ello derivó en una ausencia casi absoluta de renovación formal y de una temática diferenciada de la del teatro escrito por hombres (Arias Careaga, 2005: 187).

Así, la mayor parte de la producción de estas autoras se inserta en la línea predominante del teatro burgués y la comedia de costumbres que, en consecuencia, vehiculan fundamentalmente una moralidad católica y machista. Esta caracterización deriva ineludiblemente en la siguiente pregunta: ¿puede hablarse de dramaturgia femenina en los años del Franquismo? La crítica se muestra reticente a esta etiqueta y ofrece razones por las que no pudo consolidarse un teatro abiertamente femenino; entre otras, el conservador criterio comercial de los empresarios teatrales (O’Connor, 1990a: 390), de quien en última instancia dependía la materialización del teatro sobre las tablas. Existe, por tanto, consenso sobre el hecho de que es en la década de los ochenta cuando se normaliza completamente el papel de la mujer en el mundo teatral y cuando se gesta una dramaturgia femenina que con el tiempo haría viable, a su vez, una dramaturgia feminista (Serrano, 1999 y 2004).

Este estado de cosas imposibilita hablar de una dramaturgia femenina durante el Franquismo. Existe, sin embargo, un corpus de teatro escrito por autoras que, aunque no responda a la etiqueta de dramaturgia femenina, es de gran relevancia para entender el teatro de la época y cuyo análisis, por tanto, puede revelar interesantes perspectivas. No en vano, los lazos entre el teatro escrito por mujeres y la dramaturgia femenina no le han sido ajenos a la mayor parte de la crítica, que ha visto en el primero la antesala de la segunda. Siguiendo esta teoría, la mayoría de trabajos que se han ocupado de la dramaturgia escrita por mujeres durante el Franquismo ha prestado atención a aspectos como la construcción de roles femeninos, que anticipan la dramaturgia femenina. Las lecturas de género, pues, han sido la regla en este tipo de trabajos, que se han centrado, por otra parte, en un tratamiento fundamentalmente textual y han dejado de lado aspectos más relacionados con la puesta en escena.

Vilches de Frutos (2009 y 2010c), Urszula Aszyk (1992), Virtudes Serrano (1994a y 1994b, 1999, 2002, 2003a, 2003b y 2004), Juan Antonio Hormigón (1997) y Raquel Arias Careaga (2005), que se centran en la dramaturgia escrita por mujeres durante el Franquismo y se adentran también en el periodo democrático. Por otra parte, las historias del teatro publicadas en los últimos años, como la de Javier Huerta Calvo (2003), prestan también una mayor atención al teatro escrito por mujeres. 
Este artículo se posiciona en un enfoque menos ceñido al texto y pretende ilustrar la manera en que el estado franquista, a través de la censura teatral, conceptuó y gestionó el teatro escrito por mujeres y la presencia de las mujeres en el mundo teatral. Para ello renuncia al tratamiento meramente textual y a la lectura de género, por lo que la reflexión en torno a una dramaturgia femenina en potencia trasciende el interés teórico de este trabajo. El teatro escrito por mujeres durante los años del Franquismo se abordará, sin embargo, desde una nueva perspectiva: la de su recepción por parte del estado franquista. Porque, en efecto, con independencia de si el teatro de estas autoras vehiculaba o no una temática específica, estaba en cualquier caso determinado por una institución que mediaba entre las autoras y su público: la censura. Diversos trabajos se han ocupado de la censura ejercida sobre estas autoras, entendiéndola como un fenómeno social laxo, en cierto modo metafórico y de muy difícil cuantificación (O’Connor, 1990b; Nieva de la Paz, 2001).

En estas páginas se abordará, sin embargo, el estudio de la censura teatral ejercida por el estado franquista, cuya actividad puede rastrearse a través de los expedientes redactados por los propios censores. Esta perspectiva, complementaria a la de los estudios de género, pretende abordar desde otro ángulo el teatro escrito por mujeres y contribuir, a través de la investigación de archivo, a esclarecer la relación entre mujer, teatro y estado en el contexto franquista. Este objeto de estudio da continuidad a trabajos previos (Muñoz Cáliz, 2014; Santos Sánchez, 2013) que han abordado la censura del teatro escrito por mujeres durante los años cuarenta y cincuenta con el fin de iluminar «cómo los censores entendieron el papel de la dramaturga y cómo juzgaron la obra desarrollada por mujeres» (Santos Sánchez, 2013: 321). De este modo, el presente trabajo toma como objeto de estudio la censura teatral de la dramaturgia escrita por mujeres durante los últimos años de la dictadura, una vez producidos los cambios operados por la política de apertura del régimen franquista a partir de mediados la década de los sesenta.

La censura se había instaurado en España tras el final de la contienda civil. El 8 de abril de 1939, el régimen de Franco, responsable de un nuevo estado aún en ciernes, promulgaba las «Normas para los empresarios de espectáculos públicos». Durante más de dos décadas, estas normas y sus posteriores modificaciones guiarían la producción teatral en España. Suponían la aplicación de facto de la Ley de Prensa de 1938, una ley marcial redactada durante la guerra y que se mantendría vigente hasta 1966. Tras un breve periodo falangista inicial, los cuadros católicos del Franquismo se harían con el control de la censura con un único fin, que Gabriel Arias-Salgado, Ministro responsable del aparato censor, explicaría más tarde del siguiente modo: «Gracias a la censura previa se salvan ahora más almas en España» (en Muñoz Cáliz, 2005: 50). La censura de esa primera parte del Franquismo respondía a la doctrina de la teología de la información y su misión principal era la defensa de una férrea moral católica. La censura ejercida al teatro escrito por mujeres en esta etapa revela un claro sesgo 
de género por parte de los censores así como duros juicios a las autoras en tanto que mujeres (Santos Sánchez, 2013).

La llegada de Fraga Iribarne al Ministerio de Información y Turismo en 1962 supondría un cambio en las políticas del Franquismo que los expertos han venido en denominar apertura. Cada vez más dependiente en lo económico de los países de su entorno, la España de Franco tuvo que darse una apariencia de democratización que le permitiera afianzar el crecimiento de su economía, clave a la vez para la paz social. Como herramienta propagandística, la censura se convirtió en un aparato clave para llevar a cabo un lavado de imagen del régimen en el ámbito internacional (Muñoz Cáliz, 2005: 134): por primera vez se emitieron unas normas de censura que detallaban un listado de elementos prohibidos al tiempo que se ejercía una nueva tolerancia con el teatro de la oposición, con la dramaturgia extranjera y con figuras icónicas de la República como Lorca. Esta nueva etapa coincidía con una dramaturgia que despertaba del estado de conmoción de la posguerra, superaba el teatro de texto, abría los ojos a la fisicidad del actor y planteaba una mayor beligerancia hacia el régimen.

Pese a lo que cabría pensar, esta nueva etapa no se concretó en una explosión del número de dramaturgas. Bien al contrario, se ha apuntado que la nueva permisividad pudo haber derivado en el abandono de la dramaturgia por parte de muchas autoras, «probablemente consternadas por el componente violento y específicamente erótico del teatro» de esos años (O’Connor, 1987: 111). En efecto, la nueva fisicidad del teatro permitía una cosificación del cuerpo de la mujer que pudo determinar que muchas autoras se volcaran en otros géneros como forma de protesta. Hubo, en cualquier caso, autoras teatrales en esta nueva etapa del Franquismo. La gran mayoría continuó vehiculando en sus obras los valores de madre católica, esposa y ama de casa diligente, perpetuando así los moldes de la literatura dramática al uso. Se ha apuntado que su dramaturgia refleja siempre

una educación más estricta, [porque] ellas son más conservadoras ideológicamente, más puritanas lingüísticamente, y menos innovadoras técnicamente. Sus obras tienden a enfocar episodios románticamente idealizados y a promocionar valores tradicionales (O'Connor, 1988: 31).

A pesar de ello estas autoras partían de un punto distinto al de sus compañeras de los años cuarenta. Las dramaturgas del primer Franquismo habían introducido en sus obras algunos temas delicados, como el adulterio, aunque siempre como resorte para ofrecer un castigo ejemplar y propiciar finales aleccionadores (Santos Sánchez, 2013). Sin embargo, las jóvenes autoras de los sesenta recogían el testigo de un teatro que ya contenía estos temas y partían, por tanto, de un punto distinto al de la generación anterior.

Muy pocas de estas autoras trascendieron el anonimato (Arias Careaga, 2005: 171) y en ningún caso alcanzaron las cotas de reconocimiento de sus homólogos masculinos. Ninguna mujer se incluye de manera inapelable, por ejemplo, en las nóminas del teatro realista ni del teatro underground. Hubo, sin embargo, 
autoras que alcanzaron un relativo éxito, que se tradujo en frecuentes puestas en escena de sus títulos. Su éxito de público en aquellos años y la atención de la crítica en fechas más recientes residen en el hecho de que su teatro ofrecía ciertos elementos de contestación al férreo discurso moral del Franquismo. Se ha apuntado sin embargo que su carácter beligerante ejerció una «nula incidencia [...] sobre la marcha general del arte escénico español» (Arias Careaga, 2005: 187) por las dificultades que tuvo para estrenarse y publicarse. Entre esas dificultades figuran los impedimentos dispuestos por la censura, pero también factores comerciales o sociales más difíciles de rastrear y cuantificar.

Para ofrecer un análisis representativo de la censura de las dramaturgas durante los últimos años del régimen se tomarán como corpus los teatros de Carmen Resino y Ana Diosdado. Raquel Arias Careaga (2005) incluye a ambas en su listado de autoras de los últimos años de la dictadura y Virtudes Serrano señala a las dos como miembros destacados de una generación que no había vivido la guerra, que se vio envuelta en las revueltas estudiantiles del Franquismo y que alcanzó un relativo grado de compromiso en su teatro (Serrano, 2002: 90). Las dos son, además, las autoras que han despertado un mayor interés en la crítica académica. Por otro lado son las autoras más representadas $\mathrm{y}$, en consecuencia, existe un amplio número de expedientes de censura para sus obras. Estos expedientes incluyen, frente a los de otras autoras menos polémicas, comentarios que revisten un especial interés, en tanto que suscitaron los recelos de los censores. Estas razones, junto a la calidad de su obra y la atención crítica que han merecido, hacen de Carmen Resino y Ana Diosdado las dos autoras más representativas para entender la relación entre estado, teatro y mujer en los últimos años del Franquismo.

\section{CARMEN RESINO}

Carmen Resino (1941) comenzó su carrera dramática en la década de los sesenta y fue especialmente activa en los primeros años de la democracia. Autora de más de treinta textos teatrales, Resino ha cultivado géneros teatrales muy diversos y se ha volcado tanto en la crítica de la sociedad de consumo como en los juegos históricos (Hormigón, 1997: 1065). Para Resino

la historia [...] es un 'telón de fondo' sobre el que se 'reinventa' la realidad con muy
definidos propósitos: los de mostrar la inexorable fuerza del destino y la irónica rei-
teración de los sucesos, analizar los mecanismos del poder y evidenciar la 'inutili-
dad' que acecha al ser humano en sus actuaciones y sus anhelos (Paco, 1995: 305).

Este uso de la historia como marco sobre el que tejer ficciones ha permitido una lectura de su obra que ha destacado similitudes con autores como Muñiz, Olmo, Sastre, Rodríguez Méndez o Martín Recuerda (Paco, 1995). A pesar de que Resino «comenza a deixar oír nitidamente a súa voz desde 1983» 
dando forma a un teatro que reflexiona sobre el papel de la mujer en una sociedad de hombres (Serrano, 1999: 100), su presencia en las tablas de la época franquista no es nada desdeñable: entre 1969 y 1975 constan 6 obras de la autora presentadas a censura.

La primera solicitud de que hay constancia es la de la obra Cero en 1969. Se trata de un texto inédito que versa sobre un matrimonio sin hijos que juegan a ser padres de una niña imaginaria para evadirse de la realidad (Hormigón, 1997: 1068). La obra fue montada por el grupo teatral Karma tanto en Madrid en 19695 como en Valladolid en 1970 (Hormigón, 1997: 1068), sin que en ningún caso constasen cortes o problemas con la censura. Los comentarios agresivos contra la autora comenzarían con la siguiente solicitud, en 1970. Colisión es un drama en que la llegada de un nuevo personaje altera las vidas de un grupo hasta el punto de que finalmente deciden asesinar al extraño para recuperar la normalidad. En su solicitud para montar la obra en Valladolid en $1970^{6}$, la compañía teatral de la propia autora recibió una autorización sin cortes. Sin embargo, el expediente incluye las primeras consideraciones que menosprecian la obra. No sólo se habla de «ingenuidades a granel» y de «un léxico torpemente libresco», sino que además se afean las «derivaciones sexuales de tratamiento típicamente femenino». Estas palabras de uno de los censores dan por sentado que existe un teatro femenino, o al menos una manera femenina de abordar ciertos temas relacionados con la moral sexual. Las implicaciones de este comentario serán abordadas más adelante.

En 1972 se presentaron a censura las dos obras más polémicas de la autora durante el periodo franquista. El grupo Teloncillo de Valladolid hizo ambas solicitudes en la misma fecha, probablemente para representarlas en un festival de la ciudad. $\mathrm{La} \mathrm{sed}^{7}$ es una obra breve con formato de café-teatro en que una joven reflexiona en voz alta sobre sus deseos y anhelos sin prestar atención a su abuela, que está a su cargo y constantemente le pide agua, hasta que al final de la obra muere de sed. El texto gira en torno a los problemas de la incomunicación y la soledad (Hormigón, 1997: 1070) y cuenta con algunas escenas sórdidas. Las obse-

\footnotetext{
${ }^{5}$ Archivo General de la Administración (AGA). Expediente de censura de Cero (120/69). Los expedientes de censura contienen tanto los textos de las obras como formularios e informes sobre su proceso censor. Todos estos documentos están sin paginar y, por tanto, a lo largo del texto se ofrecerá como única referencia el número de su expediente.

${ }^{6}$ AGA. Expediente de censura de Colisión (337/70). Hormigón (1997: 1096) señala que la obra se estrenó en 1971 en la Casa de la Cultura de Palencia por parte del grupo Karma, bajo la dirección de José Luis Izaguirre, y que hubo una nueva representación en 1973 en Madrid por parte del grupo Ariostos. Los expedientes de censura generalmente no recogen informaciones sobre las puestas en escena; estas informaciones se complementan, por tanto, con los datos aportados en catálogos como los de Hormigón. Del mismo modo, los expedientes ofrecen, en muchas ocasiones, fechas y estrenos que no han sido incluidos en dichos catálogos. Este tipo de informaciones complementarias se ofrecerán en notas al pie.

${ }^{7}$ Tanto Arias Careaga (2005: 185) como Hormigón (1997: 1070) dan como fecha de estreno el montaje de 1974 en Madrid.
} 
siones sexuales de la joven saltan a escena tanto a través de las acotaciones, que la llevan a imaginar hombres a quienes acaricia, como de sus réplicas. He aquí uno de los párrafos que desató la preocupación de los censores:

¡Estoy harta, harta, harta de ser completa y monstruosamente virgen! ¡He dicho que vengas ahora mismo y me pegues y patalees si es ese el precio que quieres!... ¡Virgen! ¿No te da risa? ... Mi abuela diría que es una virtud... ... ¡claro, ¿qué van a decir para consolar? ... ¡Fregona y virgen! ¿No es totalmente lamentable? Y encima ésa ....!

La obra se aprobó para sesiones de teatro de cámara tras un debate intenso en la junta de censura: a pesar de que el protocolo normal dictaba que sólo tres censores juzgaran la obra, el expediente recoge hasta cinco informes distintos. En el manuscrito de la obra se observan numerosas tachaduras hechas por los censores que, sin embargo, finalmente no se impusieron. Estos cortes son de dos tipos. Por un lado hay dos palabras marcadas: «cabrón» y «virgen». Por otro, hay marcas en varias de las acotaciones, que hacen referencia a escenas en que la nieta se quita la ropa, palpa a un hombre imaginario, se comporta «con voluptuosidad» o jadea con pasión. Si bien las dos palabras mencionadas se mantuvieron en la versión final porque no revestían un problema especial a ojos de la censura, la imposición del visado del ensayo general garantizaba que las actitudes físicas de la actriz no sobrepasaran los estrechos límites de la moral franquista. El visado del ensayo general era un protocolo vigente desde la nueva legislación de 1964 (Muñoz Cáliz, 2005: 139) que establecía que un censor acudiera al ensayo general para comprobar que la puesta en escena respetase el texto aprobado y los aspectos escénicos derivados de las acotaciones entrasen dentro de los límites de la permisividad.

De mayor importancia para entender la actitud del régimen respecto a la concepción de la mujer son los comentarios de los censores sobre el texto. Estos definían la obra como «escenificación virulenta de dos sedes: de agua en la Abuela [...] y de hombres en la muchacha», joven «virgen, fregona y ninfómana insatisfecha». La caracterización de ninfómana es muy frecuente en los expedientes de la época y se aplica sin criterio para toda mujer que sale de la ortodoxa moral sexual del Franquismo y expresa libremente sus deseos sexuales. Si bien durante la primera parte de la dictadura esta conducta se llevaba a escena con el fin de castigarla al final de las obras, en esta nueva etapa el final redentor deja de ser necesario y el castigo llega no por parte de las autoras, sino de la censura.

Los informes señalaban también el «lenguaje desgarrado, de un naturalismo pesimista y ácido» de la obra, así como «el tono de crueldad y la subrayada sensualidad de la protagonista». Esta configuración fue la que determinó que la obra no se autorizase para el gran público, sino únicamente para sesiones de cámara, que consistían en una única ocasión para un público se-

\footnotetext{
${ }^{8}$ AGA. Expediente de censura de La sed (347/72).
} 
lecto, generalmente socios de algún club teatral (Muñoz Cáliz, 2005: 59). Uno de los censores llegó incluso a abogar por la prohibición del texto alegando «las más elementales normas del buen gusto» y no el carácter pornográfico o el ataque a la institución familiar que consideraba que la obra encerraba. El censor entiende que hacer gravitar su decisión sobre estos otros contenidos habría supuesto un «halago» para la autora. Entiende así la censura que Resino, mediante sus desafíos a la moral franquista, pretende únicamente provocar y forjarse un nombre basado en la polémica. La censura, en efecto, considera que este «tratamiento típicamente femenino» citado anteriormente busca crear una dramaturgia diferenciada. Para evitarlo la censura opta precisamente por no incidir en este carácter de provocación y por silenciarlo, ya que considera que airearlo redundaría en una mayor proyección de la autora.

Los informes de Ultimar detalles, presentada también a censura en $1972^{9}$, ahondan en esa caracterización de la autora. El texto trata sobre Lunarcitos, una vieja corista a punto de casarse con un hombre rico pero que, en el último momento, decide hacer valer su independencia frente al hombre. La temática gira por tanto en torno a la independencia de la mujer, hecho que a priori podría chocar con los estrechos márgenes de la moral franquista. Sin embargo el texto se autorizó para su estreno en Valladolid, pero fue sometido a cortes y al visado del ensayo general. Los censores, además, se refirieron de manera irreverente y con sorna a la «calidad» de la dramaturgia de la autora [entrecomillado del original], mofándose de la supuesta falta de valor literario de su texto. Lo más sorprendente de la obra, sin embargo, es un párrafo que la autora había incluido en su manuscrito, a modo de nota, y sobre el que recayeron los cortes de los censores:

\begin{abstract}
Aunque yo marco a Lunarcitos como una mujer, este papel también puede ser representado por un hombre muy grueso, vestido como de payaso, con unos lunares muy grandes en el traje o medias. El otro personaje entonces llevará vestimenta análoga pero más tipo Arlequín. Ambos han de hablar el texto normalmente y «Lunarcitos» (varón) sin ninguna voz estereotipada que parezca homosexual ${ }^{10}$.
\end{abstract}

Este episodio de travestismo debió de parecerles intolerable a los censores y no sólo lo eliminaron, sino que además impusieron el visado del ensayo general para evitar cualquier desvío en esta dirección. El hecho de que esta nota fuese añadida por la autora a posteriori sobre su propio texto revela una cierta actitud irreverente ante la censura, quizá en la línea de lo insinuado por los censores en el expediente anterior, y un tono de desafío que chocaba con los márgenes que el Franquismo había previsto para el ámbito sexual, más estrechos aún que los que imperaban en la concepción de género (Santos Sánchez, 2011).

\footnotetext{
${ }^{9}$ Hormigón (1997: 1075) da como fecha de estreno el montaje de 1984 en el Ateneo Jovellanense de Gijón por el grupo La Gotera.

${ }^{10}$ AGA. Expediente de censura de Ultimar detalles (346/72).
} 
De 1975 datan las dos últimas solicitudes a la censura para montar obras de la autora. Homotecia o Breves piezas para un teatro simultáneo, una obra con varias acciones simultáneas, fue aprobada sin problemas para el IX Festival de Teatro de Sitges ${ }^{11}$. También con la intención de estrenar en ese festival se envió una solicitud para la obra ¡Dinero, dinero!... (Fórmula tres), una comedia absurda sobre «el culto al dinero aun a costa de no disfrutar de la vida» (Hormigón, 1997: 1072-73). El texto fue aprobado sin cortes pero, aun así, los censores marcaron en el manuscrito una réplica crítica con el matrimonio: «...Y por eso [el matrimonio] sigue siendo una institución imperfecta» ${ }^{12}$. Este último reparo cierra el catálogo de contratiempos que las obras de la autora sufrieron frente al lápiz rojo de los censores, ya que no constan más expedientes de obras de Resino durante el Franquismo.

Como ha podido verse en las páginas anteriores, todos los contratiempos sufridos por el teatro de la autora con la censura pertenecen al ámbito de la moral. No hay evidencia, por ejemplo, de manifestaciones de una censura de corte más político. Este habría sido el caso, por ejemplo, de Libres en primavera, en que la autora expresa «ese miedo a la libertad, en unos años - todavía en 1970 - en los que seguía habiendo dictadura» (Hormigón, 1997: 1066). La obra, sin embargo, no consta como presentada a censura ${ }^{13}$. Lo mismo cabría haber esperado de El Presidente, obra de corte histórico ambientada en la Escocia del siglo XIII y cuyo argumento gira en torno a una serie de intrigas cortesanas. A pesar de que hay constancia de que el texto fue llevado a escena en 1970 (Arias Careaga, 2005: 185), no existe expediente censor de la obra. Estas asimetrías entre obras estrenadas y expedientes de censura son, lamentablemente, frecuentes.

Virtudes Serrano ha señalado que, a pesar de configurar «unos tipos femeninos que, aunque víctimas de su destino colectivo, luchan por cambiar las estructuras opresoras», el teatro de Carmen Resino no es un teatro feminista de bandera (1994b: 47, 29). Las obras que componen el corpus analizado presentan tratamientos heterodoxos de la moral franquista, pero los comentarios de los censores no revelan una preocupación exclusiva por los modelos propuestos de mujer, sino que abarcan una casuística más compleja de temas de moral. Además de ofrecer críticas a la calidad de su teatro, la censura encuentra problemático el cuestionamiento del matrimonio y los ataques a la familia, así como la presentación explícita de actitudes sensuales que no duda en calificar de pornografía. El caso más destacable es la aparición de un personaje travestido que, en una obra entendida como

${ }^{11}$ AGA. Expediente de censura de Homotecia o Breves piezas para un teatro simultáneo (430/75).

${ }^{12}$ AGA. Expediente de censura de ;Dinero, dinero!... (Fórmula tres) (429/75).

${ }^{13}$ Hay constancia de muchas otras obras escritas en esos años (Arias Careaga, 2005: 185186; Hormigón, 1997) que, sin embargo, no fueron estrenadas y, en buena medida, permanecen inéditas. 
alegato de defensa de las mujeres, propone una problematización añadida de los roles de género. Los censores se limitan a eliminar el episodio sin dejar más registro de su opinión al respecto, que sin duda habría arrojado luz sobre su comprensión de la diversidad sexual y de género.

Porque, y es quizá lo más interesante de los expedientes de obras de Resino, los censores entienden que hay un «tratamiento típicamente femenino» de las «derivaciones sexuales» ${ }^{14}$. Este argumento permite una comprensión del punto de vista de la censura sobre la dramaturgia de autora: que el teatro escrito por mujeres correspondía, inevitablemente, a un tratamiento específico que se dejaba notar, especialmente, en temas relativos a la moral y la sexualidad. En efecto, los problemas sufridos por la autora con la censura no se relacionan con su tratamiento de la historia, sino con su escenificación de los roles de género, el matrimonio o el sexo. Ha sido señalado que los censores encontraron impropios de las mujeres temas permitidos a los hombres ${ }^{15}$. Sin embargo, esta declaración de los censores apunta más bien en la siguiente dirección: no que los censores permitiesen a los hombres unos temas y que vetasen esos mismos temas a las mujeres, sino que estaban predispuestos a detectar especificidades en el tratamiento de esos temas y que dichas especificidades, a priori, contravenían los patrones de la moral franquista. Así, en el caso de Resino, queda ilustrado cómo el aspecto que preocupó a los censores fue el tratamiento de la moral. Sin embargo, a pesar de la lectura atenta de la censura y del férreo control que suponía el visado del ensayo general, ninguna obra fue prohibida y los tratamientos heterodoxos de la autora, aunque atenuados, fueron finalmente aprobados para la escena.

\section{ANA DIOSDADO}

Pero si una autora destaca sobre todas las demás en la década de los 70 es Ana Diosdado (1938), de la que algunas voces han señalado que «es la autora que mejor representa a la mujer en el espacio público del teatro español» (Serrano, 2002: 90). Además de estrenar sus obras con gran éxito en España, la autora ha recibido premios en Estados Unidos y América Latina y también se ha labrado una fructífera carrera en el mundo de la televisión. Actriz, directora y dramaturga, Diosdado proviene de una familia con estrechos vínculos con el mundo del teatro. Como Resino, Diosdado pertenece a una generación de autoras que no vivieron la guerra, que evitan los tonos poéticos, melodramáticos y evasionistas de las dramaturgas del primer Franquismo y que plantearon un verdadero relevo con la generación anterior: en

\footnotetext{
${ }^{14}$ AGA... Vid. supra nota 6.

${ }^{15}$ Abellán, Manuel (1982). «He bajado a los sótanos de la censura y lo he copiado todo», Actual. 32, p. 79 .
} 
1970, cuando muere Julia Maura, tiene lugar el primer éxito de Ana Diosdado. Su teatro ha sido enmarcado dentro de «un realismo un tanto crítico» (Aszyk, 1992: 51) y se ha definido como neorrealista con compromiso social (Serrano, 2003a: 2810) y con «una postura crítica frente a los valores contemporáneos» (O’Connor, 1988: 333), al tiempo que otra parte de la crítica lo ha etiquetado de comedia burguesa (Oliva, 1989: 458).

La pregunta de si el teatro de Ana Diosdado es un teatro comprometido es, en efecto, compleja. Para Phyllis Zatlin, quien más en detalle se ha ocupado del teatro de la autora, en su escritura dramática «one finds a tension between tradition and nonconformity, between the repressive conservatism of the past and a society in transition» (Zatlin, 2006: 120). Sin embargo, buena parte de la crítica cuestiona esta definición y opta por la etiqueta de teatro de consumo. Zatlin ha combatido esta categorización, que achaca a los finales felices, la esmerada construcción y el éxito comercial de las obras de Diosdado, así como a una lectura tendenciosa de críticos masculinos, que pierden «la mayor flexibilidad de la escritura femenina»(Zatlin, 1995: 135, 139, 142).

A pesar de que buena parte del teatro de Diosdado se compone de pièces bien faites, Zatlin defiende que en su dramaturgia existe una gran variedad teatral, un destacable grado de complejidad en la puesta en escena y obras de corte metafórico que cuestionan la etiqueta de teatro de consumo. Sin ánimo de enlazar el teatro de la autora con la generación realista, la lectura de Zatlin muestra las preocupaciones sociales que encierran «los primeros textos de Diosdado, al deconstruir las oposiciones binarias franquistas, logran el efecto de propaganda dialéctica... ponen en duda la dicotomía liberal/conservador, así pidiendo mayor tolerancia ideológica» (1995: 140). Esta lucha de dicotomías ahonda en una crítica a la sociedad de consumo, al capitalismo y al materialismo y supone, en última instancia, una «deconstrucción de oposiciones binarias [que] sirve de enlace con la llamada escritura femenina» ya que, a pesar de que sus mujeres no planteen un modelo de liberación, de alguna manera se lleva a cabo un cuestionamiento del patriarcado (Zatlin, 1995: 143). Lo cierto, sin embargo, es que la problemática de las obras, a pesar de su naturaleza ética, se mueve dentro de presupuestos burgueses y, como se ha apuntado, «nunca se produce una ruptura total que les obligue [a los personajes] a transformar radicalmente su vida» (Hormigón, 1997: 435).

En cualquier caso, lo cierto es que el teatro de Diosdado plantea problemas éticos y que esos problemas le llegaron al público, ya que la autora fue la dramaturga de mayor éxito durante los últimos años del Franquismo. Su permanencia en las carteleras y su éxito de público y crítica la auparon hasta el punto de ser nombrada por sus compañeras dramaturgas como ejemplo de éxito en el mundo teatral en la encuesta llevada a cabo por Estreno en 1984 (O'Connor, 1984). Estos factores han determinado que el mundo académico le haya brindado a su obra mayor atención que a la de otras autoras contemporáneas. Todo ello ha convertido a Ana Diosdado en la primera dramaturga 
de gran éxito durante los últimos años de la dictadura. Este hecho acarrea dos consecuencias. Por un lado, normaliza la presencia de la mujer en el mundo teatral y contribuye al desarrollo de una dramaturgia escrita por mujeres que, eventualmente, allanaría el camino a las dramaturgias femeninas e incluso feministas de la democracia. Por otro, determina que la censura, consciente del éxito de la autora, escrutase sus obras de manera exhaustiva. Las siguientes páginas se concentrarán en este último fenómeno.

Al margen del de una adaptación de Usinov en 1969 (Hormigón, 1997: 436; Arias Careaga, 2005: 187), el de Olvida los tambores en 1970 fue el primer estreno de una obra de Ana Diosdado. El texto se adentra en la problemática de dos matrimonios con estilos de vida opuestos: el conformismo de una vida cómoda frente a la crítica de los valores burgueses (Hormigón, 1997: 437). La trama está salpicada de reproches, adulterio y acusaciones y acaba con la muerte de uno de los personajes. Esta obra rompe la tradición femenina de escribir sobre mujeres sufridoras en los ámbitos de la familia o el amor (O’Connor, 1990a: 380) e introduce la que será la forma de gran parte del teatro de Diosdado: la comedia burguesa que deriva en drama (Zatlin, 1995: 127). Según algunas lecturas, el texto es susceptible de insertarse en la línea del teatro de Buero Vallejo o Sanchis Sinisterra en tanto que da testimonio de la vida de una serie de personajes que vive la conmoción de 1968 aún en pleno Franquismo (Serrano, 2003b).

La obra experimentó un éxito sin precedentes. Tras el estreno de Zamora en 1970 llegó el del Teatro Valle-Inclán de Madrid y, tras este, cientos de representaciones en España, Europa y América Latina, además de varios premios y una versión cinematográfica (Hormigón, 1997: 438; Zatlin, 2006). La prensa hizo recaer el éxito de la obra en la novedad de su tema ${ }^{16}$, que incluía no sólo las costumbres de una pareja moderna que decide no compartir techo, sino también una clara presencia del adulterio. Sorprende el tratamiento de la censura, que valoró la calidad del texto y lo juzgó como «buena comedia» con «conceptos más o menos críticos» ${ }^{17}$. El texto se interpretó como presentación de la problemática de las generaciones jóvenes y, a pesar del «abigarramiento y el pretendido desenfado en los conductos», los censores apreciaron que «siempre existe la contrapartida por un recondito [sic] sentido moral de los personajes». De este modo la obra fue autorizada sin cortes y con el requisito del visado del ensayo general. Así, una supuesta finalidad moralizante abría las puertas de la escena a una joven autora y le permitía consolidarse en las tablas del último Franquismo.

El único corte aplicado se ejecutó en un cantable añadido a posteriori sobre una mención explícita al «silencio» de la censura y al cada vez más próximo final de la dictadura: «Siento que está naciendo un tiempo nuevo / para los que vivi-

\footnotetext{
${ }^{16}$ La Vanguardia. Críticas de teatro: 26-I-1972: 45.

${ }^{17}$ AGA. Expediente de censura de Olvida los tambores (216/70).
} 
mos en silencio. / Siento que está naciendo un tiempo nuevo / en donde viviremos sin miedo». Con la inclusión de estas palabras pretendía Diosdado alzar un tono más su voz frente a una censura que, sin embargo, utilizó la tinta roja para evitarlo. No obstante, este corte no impediría que la obra recorriese la geografía española: 18 nuevas solicitudes hacen de la obra una de las más presentadas a la censura durante el Franquismo. Aún en 1972 se seguía representando en Madrid y había estado ya tres meses en cartel en Barcelona ${ }^{18}$. No es de extrañar que este éxito sin precedentes de una autora novel crease grandes expectativas por su segunda obra, cuya temática histórica ya se había adelantado ${ }^{19}$.

Antes de este esperado estreno, que como se verá más adelante tuvo problemas con la censura, se produjo el de otra obra. El okapi narraba la llegada a una residencia de ancianos de un vagabundo que contagia al resto sus ganas de vivir. La obra muestra «un conflicto particular de cada uno de los ancianos que revisa su aburrida vida» (Hormigón, 1997: 439); hay, además, quien ha efectuado una lectura más politizada: la obra permite la «recuperación de la memoria lejana de quienes padecieron la represión durante la posguerra», que en el presente de la obra son ancianos en una residencia (Serrano, 2003b: 120). Desde el punto de vista escénico, el texto presenta una mayor complejidad que Olvida los tambores al crear una serie de espacios gracias a un hábil juego de luces. El estreno se produjo en enero de 1972 en el Teatro Álvarez Quintero de Sevilla y aquel mismo año se puso en escena en el Teatro Lara de Madrid (Hormigón, 1997: 438). La crítica también se ha hecho eco del gran éxito de público y crítica del montaje (Zatlin, 1995: 126).

Los censores valoraron positivamente la construcción de los tipos, la eficacia del lenguaje y la temática de la obra, que suponía «una exaltación de los ancianos, una preocupación por sus problemas humanos, por su existencia en si [sic] como seres vivos que merecen una atención directa y entrañable» ${ }^{20}$. Se tachó también de «comedia dura, a veces amarga» por la muerte del protagonista, por lo que se tildó de «muy humana, aunque la conclusión sea un tanto pesimista». El texto se aprobó con la condición del visado del ensayo general. La solicitud la había realizado a finales de 1971 Enrique Diosdado, padre de la autora y director teatral, para montar el espectáculo en una gira por provincias que, según lo apuntado más arriba, debió de comenzar en Sevilla.

La autorización se produjo, sin embargo, con otra condición: la sustitución de una pareja de Guardias Civiles, que aparece de manera puntual, por agentes de «otro cuerpo menos caracterizado». A pesar de que en esta mención a la Guardia Civil no se observe intencionalidad política ninguna, la censura prefirió que una de las instituciones básicas del régimen franquista no fuese llevada a escena. El corte no afectó a la estructura ni al argumento de la obra,

\footnotetext{
${ }^{18}$ La Vanguardia. Críticas de teatro: 26-I-1972, p. 45.

${ }^{19}$ La Vanguardia. Críticas de teatro: 4-XII-1971, p. 63.

${ }^{20}$ AGA. Expediente de censura de El okapi (638/71).
} 
que le valió un nuevo éxito a la autora. La técnica, la humanidad en el tratamiento del tema, la ausencia de melodramatismo y la combinación de diversión y ternura que planteaba el texto le valieron los elogios de la prensa a Diosdado, a quien se describió como «una autora joven que "sab[ía] hacer teatro" $\gg^{21}$. Frente al duro tratamiento recibido por autoras como Julia Maura durante los primeros años del Franquismo (Santos Sánchez, 2013), los elogios a Diosdado tanto por parte de la crítica como de la censura constituyen una absoluta novedad.

Los comuneros, la obra de corte histórico que público y crítica esperaban con gran anhelo, le valió a la autora problemas más serios con la censura. El texto gira en torno al alzamiento de los comuneros en la Castilla del siglo XVI. Para ello, Diosdado recurre al punto de vista de Carlos V en diferentes momentos de su vida: su juventud, su madurez y su lecho de muerte. Este juego espacial le permite a la autora reelaborar la historia y analizar los hechos desde diversos momentos (Arias Careaga, 2005: 187). La legitimidad de la violencia ejercida desde el poder, representado por Carlos V, es el tema principal de la obra. Existen también interpretaciones en clave feminista centradas en la figura de Juana la Loca (López y Marino Segura, 2007), así como otras en clave política, que entienden que «Diosdado está juzgando desde la historia al dictador y su derecho a matar escudado en su autoridad» (Serrano, 2003b: 124125). Según estas últimas, «la imagen de una Juana la Loca, encerrada en su castillo-prisión, se multiplica en forma de los miles de personas detenidas por representar una posible amenaza durante la guerra civil y la posguerra» y se apunta a un conflicto entre «un pueblo republicano y un poder político fascista» (Zaza, 2007: 164, 54). Si bien los censores no hacen mención alguna al posible tratamiento feminista de Juana la Loca, estas interpretaciones políticas no habrían de pasarles inadvertidas.

Aunque la autora había declarado que su obra no era teatro-documento y que, por tanto, no tendría problemas con la censura ${ }^{22}$, lo cierto es que el trámite no resultó tan sencillo. En efecto, a pesar de que algunos críticos fechan la redacción de la obra en 1974 (Serrano, 2003b: 124; Hormigón, 1997: 441), lo cierto es que Los comuneros ya estaba escrita en 1972, año en que la compañía de Luis Pellicena la presentó por primera vez a las autoridades censoras. Según el expediente la obra fue autorizada ${ }^{23}$; sin embargo, el estreno no se produjo hasta 1974, en el Teatro Nacional María Guerrero de Madrid, según recogen tanto la crítica (Zaza, 2007: 48; Hormigón, 1997: 441; Serrano, 2003b: 130-131; Zatlin, 1995: 125) como la prensa ${ }^{24}$.

\footnotetext{
${ }^{21}$ La Vanguardia. Críticas de teatro: 5-V-1972, p. 41.

${ }^{22}$ La Vanguardia. Críticas de teatro: 26-I-1972, p. 45.

${ }^{23}$ AGA. Expediente de censura de Los comuneros (335/72).

${ }^{24}$ La Vanguardia. Críticas de teatro: 16-I-1974, p. 55; La Vanguardia. Críticas de teatro: 8-III-1974, p. 52.
} 
Se ha apuntado que Los comuneros es una de las pocas obras escritas por mujeres que hablan sobre la guerra (Zaza, 2007: 67; O’Connor, 1990a: 382). Como habría cabido esperar, los censores manifestaron su preocupación al respecto. El censor Ruiz Martínez contempla con preocupación la doble posibilidad de montaje del texto: por un lado «dentro de los cánones establecidos para el teatro ilusionista - ambientación general adecuada a la época y escenificación completa dentro del espacio del escenario», para la que no cabría objeción alguna por parte de la censura; o, por otro, «de acuerdo con los cánones identificables con el teatro criticista - teóricamente y de participación, es decir, empleando la sala para el alzamiento comunero y la guerra civil». Esta segunda opción se percibió como una amenaza, ya que la rememoración de un evento del pasado podía emplearse, como había sucedido ya con numerosas obras de la generación realista, como metáfora de sucesos que, como la Guerra Civil, pertenecían al presente o al pasado reciente. El censor hacía explícito, en efecto, el peligro en el uso de «símbolos identificables con los de nuestra guerra civil, como por ejemplo, las flechas, música, o [...] el ambiente de decorados y figurines».

Otro de los censores, sin embargo, reconocía la calidad de la obra con independencia del uso que pudiera hacerse de la historia: «Cualquiera que sea la postura que se quiera adoptar frente a los hechos historicos [sic] a que se refiere la obra, hay que reconocer los valores dramaticos [sic] y la seriedad del relato». Así las cosas, el texto se autorizó sin cortes, para mayores de 18 años pero con el condicionamiento de que su puesta en escena correspondiese «a una ambientación general adecuada a la época y escenificación completa dentro del espacio del escenario, sin empleo de símbolos, música y elementos complementarios de montaje identificables con los de epoca [sic] actual». De este modo la censura autorizaba la puesta en escena siempre y cuando el montaje se atuviera a una interpretación ortodoxa y no actualizadora del marco histórico original del texto.

Para ejercer este control se le exigieron a la compañía tanto los figurines como los bocetos de los decorados. La autorización definitiva de la obra quedaba, además, vinculada al visado del ensayo general de la misma, en que los censores debían comprobar si el montaje final se correspondía con las condiciones aprobadas:

La vigencia de la autorización otorgada al texto literario que se acompaña queda supeditada a la aprobación por los Servicios de Inspección del Departamento previo visado de ensayo general de la puesta en escena, realización, vestuario, interpretación, elementos complementarios de montaje, etc.

Parece que ni la solicitud de Madrid ni otra de Barcelona, con fecha de agosto de 1972, fueron finalmente autorizadas, ya que no hay evidencia de ningún montaje aquel año. El escenario más probable es que el visado del ensayo general no llegase a expedirse ante recelos por parte de los censores 
de que los vínculos con la Guerra Civil, aunque no se hiciesen explícitos, pudiesen resultarle lo suficientemente claros al público. De este modo, aunque la propia Diosdado había negado explícitamente la actualización histórica de su texto, los censores intuyeron en el uso de la historia un recurso crítico y bloquearon su representación, que quedó en suspenso.

Mientras se producía la autorización de Los comuneros, en 1973 la autora estrenaba Usted también podrá disfrutar de ella, «una denuncia contra esa manipulación tan feroz que es la publicidad» (Hormigón, 1997: 440). La obra ofrece una reflexión crítica sobre la sociedad de consumo, encarnada en las figuras de un publicista y una modelo que desgranan amargamente el verdadero trasfondo de sus vidas, regidas por las imposiciones sociales y económicas. Por su compromiso ético y social, la obra ha sido asimilada a los trabajos de la generación realista (Serrano, 2003b: 130) e incluso definida como «un ejemplo inexcusable del mejor teatro español de la segunda mitad del siglo XX» (2003b: 122). Su espacio escénico innovador, que permite desplazamientos entre varios lugares y tiempos, fue también apuntado como uno de sus logros y se valoró muy positivamente en la prensa ${ }^{25}$. Fuese por su contenido o por su concepción escénica, la obra cosechó un gran éxito de público a lo largo de sus más de 500 representaciones (Zatlin, 1995: 126).

Los censores reconocieron de manera unánime la calidad de la obra y alabaron su carácter experimental, sus diálogos e incluso su dureza, si bien manifestaron sus preocupaciones por el suicidio que cerraba el texto: «Obra profunda y amarga. No hay soluciones para romper los lazos en los que el hombre está enredado» ${ }^{26}$. Sin embargo, consideraron que la obra podía autorizarse ya que, a pesar del suicidio, «hay un llamamiento [...] a luchar por la vida y por las personas que nos rodean». De este modo la obra se aprobó, aunque se impusieron dos condiciones. Por un lado se hacía un corte en un fragmento en que, de manera tangencial, se mencionaba a ETA, que en aquel momento suponía un verdadero problema para un régimen que quería mostrarse inquebrantable. Por otro, se imponía el visado del ensayo general para controlar la proyección de un desnudo femenino que había despertado la curiosidad del público y acabaría convirtiendo el estreno en un éxito de taquilla (O'Connor, 1990a: 380). Sin embargo, los censores no mencionan en sus informes ninguna implicación de género que la crítica sí ha observado en la obra (Zatlin, 2006: 122).

Finalmente Los comuneros se estrenaba en 1974 en el Teatro María Guerrero de Madrid tras, según cabe suponer, largas negociaciones con la censura. Sin embargo, pese a la expectación que el texto había despertado entre público y crítica, parece que su recepción fue un tanto fría (O’Connor, 1990a: 382). Algo parecido sucedió con el estreno de... Y de Cachemira, chales, que

\footnotetext{
${ }^{25}$ La Vanguardia. Críticas de teatro: 6-X-1974, p. 59.

${ }^{26}$ AGA. Expediente de censura de Usted también podrá disfrutar de ella (342/73).
} 
tuvo lugar en 1976, tras la muerte del dictador pero con una censura aún vigente $^{27}$. En la obra, los supervivientes de una catástrofe nuclear viven en un centro comercial y se debaten entre si salir o no al mundo exterior. Además de como crítica al consumismo de la sociedad franquista (Zatlin, 1995: 130), el texto ha sido interpretado como «una parábola del fin de la dictadura y del intento de persistencia del opresor» sobre una generación que ha vivido completamente alienada (Serrano, 2003b: 127). La obra, estrenada en septiembre de 1976 en el Teatro Valle-Inclán de Madrid, fue aprobada sin cortes y con visado del ensayo general para controlar varios episodios de violencia que jalonaban el texto.

La fría acogida de estas dos últimas obras llevó a la autora a refugiarse temporalmente en la redacción de guiones televisivos. En 1986, Diosdado regresaba a las tablas con su farsa Cuplé, que inauguraba un registro más cómico, al que seguirían obras de una temática más realista y de ambiente actual. En este nuevo teatro se observa de manera más clara un análisis de los roles de género, las relaciones matrimoniales, la familia o el divorcio, si bien sus personajes continúan aún «at the brink of change: they reject the mold of traditional sex roles but can't quite break out of it, at least not alone» (Zatlin, 2006: 123, 126). Este teatro, sin embargo, por estar libre de una censura que había dejado de existir formalmente en enero de 1978 (Muñoz Cáliz, 2005: 409), escapa ya al marco temporal de este trabajo.

Lo mostrado en las páginas anteriores muestra divergencias en el tratamiento que la censura dio a los teatros de Resino y Diosdado. Lo más destacable es la ausencia de críticas en los juicios a los textos de Diosdado, hecho que contrasta fuertemente con las críticas que se observaban en los informes de obras de Carmen Resino. Abundan, al contrario, los aplausos a la calidad dramática, tanto literaria como escénica, del teatro de Diosdado. Por otra parte, y también en oposición a lo observado en la censura de textos de Resino, los problemas de Diosdado con la censura no se relacionan con la moral. Es cierto que su teatro incluye aspectos de índole moral; pero sin embargo la censura, siempre dispuesta a encontrar el peligro donde apenas se podía intuir, no observó que entrañasen un especial peligro.

Cabría, por tanto, esperar que sus problemas hubiesen sido de orden más político. Sin embargo, a pesar de que buena parte de la crítica ha notado que el teatro de Diosdado sirve como propaganda dialéctica que cuestiona «la dicotomía liberal/conservador, así pidiendo mayor tolerancia ideológica» en el seno del Franquismo (Zatlin, 1995: 140), lo mostrado en las páginas anteriores obliga a relativizar esta aseveración. Los únicos cortes registrados se hacen a menciones directas a instituciones del régimen franquista (la censura o la guardia civil) o a la banda terrorista ETA. Pero, como se indica en los propios informes, estas menciones son siempre tangenciales y su eliminación no

${ }^{27}$ AGA. Expediente de censura de ...Y de Cachemira, chales (1129/76). 
repercute en el conjunto de la obra. La censura no observa, además, una intención claramente política por parte de la autora en estas menciones, que entiende como aisladas y anecdóticas y, si decide eliminarlas, es únicamente por rutina preventiva.

El único problema grave de la autora con la censura tuvo lugar en el proceso de Los comuneros. Si bien la obra fue autorizada formalmente, tal y como queda apuntado más arriba, lo más probable es que la autorización final, pendiente del visado del ensayo general, nunca llegase a producirse. Hay quien ha buscado tras esta prohibición lecturas de género (Zatlin, 1995: 141), que no se rastrean en ningún caso en las palabras de los censores. Al contrario, esta prohibición se inserta en el contexto de prohibiciones similares de autores realistas que pretendían, a través de trasfondos históricos, cuestionar situaciones del presente. Ana Diosdado, aunque sin la virulencia de otros dramaturgos más comprometidos de la generación realista, perseguía una lectura actualizadora que la censura evitó. La opción más verosímil es que el montaje incluyese alusiones a la Guerra Civil y que los funcionarios no expidiesen el visado. Las negociaciones entre la compañía y la censura debieron prolongarse, como sucedía con frecuencia, hasta que el montaje se viese despojado de elementos no aceptables para los censores. Cuestiones logísticas y de calendario del mundo del espectáculo habrían determinado, una vez alcanzado un acuerdo con la censura, el retraso del estreno hasta 1974.

Sin embargo, lo más llamativo de los procesos censores de obras de Ana Diosdado es que no existe en ellos mención alguna a su condición de mujer. Mientras que los censores observaban en el teatro de Carmen Resino un «tratamiento típicamente femenino» de una serie de temas (principalmente los relacionados con el sexo), nunca aducen una especificidad femenina para la obra de Diosdado. Este hecho supone una novedad en el contexto del Franquismo, ya que la censura se amparó siempre en la casuística de género de las autoras para criticar sus textos y someterlos a clichés, no únicamente durante la primera parte del régimen (Santos Sánchez, 2013), sino también con autoras más tardías como Resino. Ana Diosdado, dramaturga en buena medida inserta en la corriente del teatro comercial, es la primera autora de éxito que escapa a los comentarios sesgados y machistas de la censura. Así, por primera vez, la censura juzga a una autora sin tener en cuenta su condición de mujer y normaliza, por tanto, la labor de las dramaturgas.

La ausencia de la etiqueta femenino en los informes de los censores puede responder a varios factores. Por un lado, es cierto que su teatro es de mayor calidad formal que el de otras autoras del Franquismo y los censores así lo perciben y lo hacen constar en sus informes. Por otro lado, la censura tiende a ver lo femenino detrás de un tratamiento específico de ciertos temas de corte moral/sexual. Si bien es cierto que los marginales problemas de Diosdado con la censura derivan más bien de su tratamiento de temas de corte más político/social, sus obras abordan no obstante también problemas de pareja e 
incluso un desnudo femenino, hechos que le valieron comentarios adversos entre los censores. Estos parecieron, en cualquier caso, no primar, como si la adecuación de la autora a los patrones generales del teatro comercial y su mayor calidad la hicieran invisible en tanto que mujer y permitieran que se la juzgase con mayor asepsia, independientemente de su condición de mujer y sólo en tanto que integrante del teatro comercial, dominado por hombres.

\section{CONCLUSIONES}

Este recorrido por las dramaturgias de Carmen Resino y Ana Diosdado ilustra el modo en que el último Franquismo, encarnado en su censura, comprendió y conceptuó el teatro escrito por mujeres, por una parte, y el rol de la mujer en el mundo teatral, por otra. Una primera idea que se extrae del panorama esbozado en las páginas anteriores es que la censura entendió que en el teatro existía un «tratamiento específicamente femenino» de temas de heterodoxia moral y sexual. Aunque la crítica retrase la llegada del teatro femenino hasta la etapa democrática, lo cierto es que la censura entiende que este teatro comienza a forjarse durante la dictadura y que su característica fundamental reside en el tratamiento de la libertad de la moral sexual. En efecto, el adulterio, la prostitución, el divorcio o incluso la homosexualidad, tematizados en diferentes grados a lo largo de los casi cuarenta años de la dictadura, parecen monopolizar los problemas de las autoras con la vigía censora (Santos Sánchez, 2013). Las críticas que estos temas despertaron entre los censores fueron virulentas y siempre se asociaron al hecho de que fuese una mujer quien les diese voz. El resto de temas se observó con menor preocupación y las alusiones políticas, generalmente leves, fueron pasadas por alto como anecdóticas y simplemente suprimidas sin despertar comentarios machistas.

Este «tratamiento específicamente femenino» es, no obstante, muy dispar en los diferentes momentos de la dictadura. En las décadas de los 40 y 50 las autoras tratan, a través de un teatro eminentemente textual, de insertar en sus obras temas como el adulterio, siempre sometidos a un final aleccionador que acabe posibilitando la representación: la adúltera, la indecente y la heterodoxa son castigadas frente a la mujer ángel del hogar, con lo que la moralina de la obra la hace apta para las tablas (Santos Sánchez, 2013). Más tarde, la apertura de las políticas culturales del Franquismo desde mediados de los 60 traería consigo el cambio de paradigma de un teatro eminentemente textual a otro donde los elementos no verbales cobraban una mayor importancia. Los visados del ensayo general, dirigidos a poner orden en una puesta en escena que cuestionaba los límites de la moral sexual franquista a través de insinuaciones físicas, se acabarían convirtiendo en una constante. Los finales aleccionadores dejaban de justificar personajes y comportamientos heterodoxos, que se ofrecían como nuevos modelos para una sociedad en que el ángel del hogar 
había perdido su monopolio. Los cortes y la restricción de los estrenos a teatros de cámara fueron las herramientas con que la censura intentó minimizar el impacto de este teatro que, sin embargo, llegó a su público y registró grandes éxitos de cartelera.

Un segundo aspecto a tener en cuenta es el modo en que la censura juzga el papel de las dramaturgas y su presencia en el mundo teatral. Este aspecto se deja rastrear de manera clara a través de las críticas de los censores a las autoras en tanto que mujeres. Durante el primer Franquismo estas críticas son constantes y muy ácidas (Santos Sánchez, 2013). Su punto de partida suele ser la baja calidad literaria y escénica de sus textos, que sirve para atacar a las autoras con comentarios insultantes e incluso groseramente machistas, estableciendo un criterio implícito de género en el quehacer censor. De este modo los censores se dirigían a las autoras en tanto que mujeres y no en tanto que dramaturgas. La dureza de los ataques respondía a un ambiente generalizado de machismo que se propagaba también a través de la prensa y que en casos como el de Julia Maura determinó que algunas autoras abandonasen la escritura dramática (O’Connor, 1992).

En esta segunda etapa, sin embargo, las críticas de índole estética son mucho más escasas. A pesar de que la calidad de los textos de las autoras es mayor, Resino continúa recibiendo agrias críticas. La diferencia fundamental es, sin embargo, que estas críticas no van acompañadas de un sesgo de género. Esta nueva realidad responde a un cambio de tendencia que se acusa aún más en el caso de Ana Diosdado, cuyas obras no sólo no reciben críticas, sino que son objeto de sinceras alabanzas en virtud de su calidad. La España de los años setenta es radicalmente distinta a la de los cuarenta y, como se observa en esta nueva tendencia, los censores fueron normalizando la presencia de las mujeres en el mundo teatral hasta el punto de evaluar el teatro de Diosdado con independencia de su condición de mujer y en función de los mismos parámetros con que juzgarían el teatro de cualquier otro autor. La comprensión de la relación entre mujer y teatro del último Franquismo queda por tanto clara y contrasta respecto a la situación vivida por las dramaturgas de la generación anterior.

Esta normalización del papel de las dramaturgas responde a varios factores. El primero es, sin duda, la apertura del régimen, que busca normalizar en cierta medida una serie de corpus teatrales, entre los que se encuentran el de los autores del exilio o la dramaturgia extranjera, que hasta mediados de los años sesenta se han evitado pero que ahora pasan a usarse como herramienta de propaganda en el exterior (Muñoz Cáliz, 2005: 143, 148). En esta serie de dramaturgias hay que incluir la de las autoras, que en esos años cuenta con figuras de gran calidad. De este modo, el régimen de Franco podía hacer gala en el extranjero, con el fin de dar una apariencia de falsa democratización, no sólo de una nueva tolerancia respecto a las dramaturgias de figuras como Lorca o Alberti, sino también respecto a las dramaturgias de mujeres. 
Un segundo factor es el gran éxito de público. Este trabajo muestra que estas autoras llegaron a las tablas y que su teatro tuvo un impacto considerable en la sociedad gracias a sus numerosas puestas en escena. Salvo la suspensión temporal de Los comuneros, no hay obras prohibidas en el corpus analizado. Así, a pesar de las trabas de la censura, los textos acabaron llegándole a un público que tanto Resino como Diosdado supieron conquistar. Las razones de este éxito responden a dos aspectos: si por un lado las autoras trataron temas que cuestionaban en cierta medida el status quo de la moral franquista, por otro supieron dar forma a un teatro de gran fuerza comercial. Esta combinación de fenómenos permitió el éxito que, a su vez, traería consigo la normalización de la figura de la dramaturga por parte del público. Esta aceptación mayoritaria por parte de la sociedad, especialmente en el caso de Ana Diosdado, es determinante para que la censura normalizase a estas autoras, que en última instancia fueron apoyadas e incluso demandadas por el público.

La tercera razón es de orden más formal. La censura sigue siendo consciente de que existe un «tratamiento femenino» específico de temas de moral y sexualidad. Sin embargo, el hecho de que Diosdado diversifique esta temática al incluir en su teatro una problemática, aunque leve, de corte más histórico o político, permite que los censores lean el teatro de la autora no exclusivamente en clave femenina, ya que contiene aspectos que ellos no achacan a la escritura de las autoras. A ello se suma el hecho de que Diosdado se inserta en la corriente del teatro comercial y entra, por tanto, en el molde formal que durante los años del Franquismo más inocuo había resultado para la censura. La conjunción de estos factores determina que la censura no le presuponga a Diosdado una intención específica de género y ello, a su vez, redunda en la normalización de su figura como dramaturga; es decir, trae consigo la capacidad de la censura para juzgar su teatro al margen de factores de género.

Pero, ¿renuncia la autora explícitamente a tener una voz específicamente femenina? A lo largo del trabajo se han mencionado lecturas críticas que apuntan en direcciones opuestas. En cualquier caso, como se apuntaba al inicio del artículo, no es la finalidad de este trabajo responder a esa pregunta. Lo crucial para este artículo es poner de relieve que es precisamente el cambio de paradigma en la obra de la autora, al alejarse de lo que la censura había etiquetado grosso modo como dramaturgia femenina, lo que permite su normalización por parte del estado franquista a través de la censura. Porque en Ana Diosdado se normaliza, como se ha visto, la profesión de dramaturga en la sociedad española del final del Franquismo. Este hecho es independiente de si su deriva dramática se debe a una reflexión de no asumir una dramaturgia femenina en ciernes o bien a una voluntad consciente de llegarle al público a través de un teatro comercial al que, a su vez, dicho tratamiento temático podía resultarle ajeno. Sus implicaciones para el desarrollo posterior de una dramaturgia femenina son, sin embargo, más patentes. 
A lo largo del trabajo se ha indicado que ni los textos de Resino ni los de Diosdado configuran una dramaturgia femenina, a todas luces dificultada por la censura. Existen, sin embargo, interpretaciones en clave de género ya desde las autoras de los primeros años del Franquismo, como Julia Maura, que crearon fisuras en el monopolio masculino del mundo teatral, y cuyo testigo recogerían Resino y Diosdado. Estas lecturas de género avant la lettre señalan en las obras de estas autoras una serie de temas y tratamientos femeninos que aparecen, sin embargo, más insinuados que desarrollados. Este germen, cabe argumentar, se desarrollaría posteriormente durante la transición y el comienzo de la democracia hasta derivar en un teatro claramente femenino e incluso feminista.

Este trabajo propone, sin embargo, que otros factores jugaron también un rol importante en dicho desarrollo. La normalización del papel de la mujer dramaturga conseguida en la década de los setenta es, en efecto, requisito sine qua non para el desarrollo de estas teatralidades femeninas y feministas, que habrían sido inconcebibles si las autoras de la democracia no hubiesen contado con antecedentes de autoras de gran impacto. Así, las autoras del último Franquismo actuaron de eslabón intermedio en el proceso de aceptación por parte del estado franquista de que la mujer podía desempeñar un rol destacado en el mundo teatral. Finalmente, con el teatro de Ana Diosdado, la dramaturgia de autora, que no femenina, se ve por primera vez completamente normalizada por parte de la censura y conquista un respeto para la mujer dramaturga que no existía en España desde la Segunda República. Por tanto, aunque su discurso no sea susceptible de etiquetarse como femenino, la presencia de estas autoras es de gran relevancia para la consecución de un discurso propiamente femenino en los años siguientes. Autoras como Resino y Diosdado engrosan, por tanto, una generación de dramaturgas que efectuaron el tránsito entre los años más duros de la dictadura y la España democrática. La importancia de su trabajo, no siempre reconocida, debe al menos legitimar y garantizar su estudio y su presencia en el discurso académico.

\section{BIBLIOGRAFÍA CITADA}

Arias Careaga, Raquel (2005). Escritoras españolas (1939-1975): poesías, novela y teatro. Madrid: Laberinto.

Aszyk, Urszula (1992). «Las mujeres dramaturgas en España: en busca de la identidad», en Lou Charnon-Deutsch (ed.), Estudios sobre escritoras hispánicas en honor de Georgina Sabat-Rivers. Madrid: Castalia, pp. 45-61.

Aznar Soler, Manuel (1993). «María Teresa León y el teatro español durante la Guerra Civil», Anthropos. 148, pp. 25-34.

Checa Puerta, Julio E. (2009). «María Martínez Sierra, una escritora en el exilio», en Pilar Nieva de la Paz (ed.), Roles de género y cambio social en la literatura española del siglo XX. Amsterdam - Nueva York: Rodopi, pp. 207-228. 
Gallego Méndez, María Teresa (1983). Mujer, falange y franquismo. Madrid: Taurus.

Hormigón, Juan Antonio (dir.) (1997). Autoras en la historia del teatro español: 1500-1994. Madrid: Publicaciones de la Asociación de Directores de Escena de España.

Huerta Calvo, Javier (ed.) (2003). Historia del teatro español. Madrid: Gredos.

López, Kimberle S. y Ángela Marino Segura (2007). «Revisiting "La locura de amor": representations of Juana la loca in Spanish theatre», Estreno. 32, 2, pp. 29-41.

Miró, Emilio (1992). «La contribución teatral de Concha Méndez», en Dru Dougherty y Vilches de Frutos, El teatro en España. Entre la tradición y la vanguardia. 1918-1939. Madrid: Tabapress, pp. 439-451.

Muñoz Cáliz, Berta (2005). El teatro crítico español durante el franquismo, visto por sus censores. Madrid: Fundación Universitaria Española.

Muñoz Cáliz, Berta (2014). «El teatro de María y Gregorio Martínez Sierra ante la censura franquista», en Francisca Vilches de Frutos (coord.), Género y exilio teatral republicano: entre la tradición y la vanguardia. Amsterdam - Nueva York: Rodopi, pp. 135-150.

Nieva de la Paz, Pilar (1992). «Tradición y vanguardia en las autoras teatrales de la preguerra: Pilar Millán Astray y Halma Angélico», en Dru Dougherty y María Francisca Vilches (ed.), El teatro en España. Entre la tradición y la vanguardia (1918-1939). Madrid: CSIC, pp. 429-438.

Nieva de la Paz, Pilar (1993). Autoras dramáticas españolas entre 1918 y 1936 (texto y representación). Madrid: CSIC.

Nieva de la Paz, Pilar (2001). «La escenificación de los roles sexuales y la censura de género durante el franquismo: el caso de Julia Maura», Iberoamericana. 2, pp. 165-180.

Nieva de la Paz, Pilar (2004). «Luces y sombras de la nueva identidad femenina en el teatro español actual», en Wilfried Floeck y María Francica Vilches (ed.), Teatro y sociedad en la España actual. Madrid - Frankfurt: Iberoamericana, pp. 65-86.

Nieva de la Paz, Pilar (ed.) (2009a). Roles de género y cambio social en la literatura española del s. XX. Ámsterdam - Nueva York: Rodopi.

Nieva de la Paz, Pilar (2009b). «La evolución de los roles de género en las representaciones literarias: un camino abierto hacia el cambio social», Foro Hispánico. 34, pp. 9-20.

O’Connor, Patricia W. (1984). «Encuesta: ¿Por qué no estrenan las mujeres en España?», Estreno. 10, 2, pp. 12-25.

O’Connor, Patricia W. (1987). «Las dramaturgas españolas y la "otra censura"», en Manuel L. Abellán (ed.), Censura y literaturas peninsulares. Ámsterdam: Rodopi, pp. 99-117.

O’Connor, Patricia W. (1988). Dramaturgas españolas de hoy (una introducción). Barcelona: Fundamentos.

O'Connor, Patricia W. (1990a). «Women Playwrights in Contemporary Spain and the MaleDominated Canon», Signs. 15, 2, pp. 376-90.

O'Connor, Patricia W. (1990b). «Censorship of the Franco era and women dramatists», en Juan Fernández Jiménez, José Julián Labrador y L. Teresa Valdivieso (coord.), Estudios en homenaje a Enrique Ruiz-Fornelles. Pennsylvania: ALDEEU, pp. 460-65.

O'Connor, Patricia W. (1992). «Julia Maura: lark in a hostile garden», en Lou CharnonDeutsch (ed.), Estudios sobre escritoras hispánicas en honor de Georgina Sabat-Rivers. Madrid: Castalia, pp. 233-245.

O'Connor, Patricia W. (2007a). «Estreno de la boda de Carmen Resino», Estreno. 33, 2, pp. 3-4.

O’Connor, Patricia W. (2007b). «Carmen Resino: una autora audaz fiel a su estilo», Estreno. 33,2 , pp. 7-10.

Oliva, César (1989). El teatro desde 1936. Madrid: Alhambra.

Oliva, César (2003). «La práctica escénica de María Teresa León», en Gonzalo Santonja (ed.), Homenaje a María Teresa León. Madrid: Sociedad Estatal de Conmemoraciones Culturales, pp. 253-265. 
Paco, Mariano de (1995). «El teatro histórico de Carmen Resino», Anales de Literatura Española Contemporánea. 20, 3, pp. 303-14.

Pérez-Rasilla, Eduardo (2003). «Las dramaturgas y el exilio: notas para un estudio de la mujer en el exilio», ADE Teatro: Revista de la Asociación de Directores de Escena de España. 98, pp. 32-36.

Primo de Rivera, Pilar (s.f.). Discursos, Circulares, Escritos. Madrid: Afrodisio Aguado.

Roca i Girona, Jordi (1996). De la pureza a la maternidad. La construcción del género femenino en la postguerra española. Madrid: CSIS.

Santos Sánchez, Diego (2011). «Sexed Bodies in the Theatre of Franco's Spain», en A. del Pozo (ed.), La piel en la palestra: estudios corporales. Barcelona: EdiUOC, pp. 255262.

Santos Sánchez, Diego (2013). «Dramaturgas y censura en el primer Franquismo: Pilar Millán Astray y Julia Maura», Revista Canadiense de Estudios Hispánicos. 37, 2, pp. 319338.

Scanlon, Geraldine M. (1986). La polémica feminista en la España contemporánea (18681974). Madrid: Akal.

Serrano, Virtudes (1994a). «Hacia una dramaturgia femenina», Anales de la Literatura Española Contemporánea. 19, 3, pp. 343-364.

Serrano, Virtudes (1994b). «Las otras voces del teatro español: Carmen Resino», España contemporánea. $7: 2$, pp. 27-48.

Serrano, Virtudes (1999). «A autoría feminina no teatro español do século XX», Revista galega do ensino. 25 , pp. 93-110.

Serrano, Virtudes (2002). «Autoras dramáticas en la España de la dictadura», Cuadernos del Lazarillo. 22, pp. 88-91.

Serrano, Virtudes (2003a). «Los autores neorrealistas», en Javier Huerta Calvo (ed.), Historia del teatro español. Madrid: Gredos, pp. 2789-2819.

Serrano, Virtudes (2003b). «El primer teatro de Ana Diosdado en la recuperación de la memoria histórica de nuestro tiempo», Hecho teatral: revista de teoría y práctica del teatro hispánico. 3, pp. 113-133.

Serrano, Virtudes (2004). «Dramaturgia femenina fin de siglo: estado de la cuestión», Arbor. 699-700, pp. 561-72.

Vilches de Frutos, Francisca (2009). «Representaciones de género en las artes escénicas. Angélica Lidell y el discurso de la transgresión», Hispanística XX. 27, pp. 277-291.

Vilches de Frutos, Francisca (2010a). «Mujer, esfera pública y exilio: compromiso e identidad en la producción teatral de Luisa Carnés», Acotaciones. 25, pp. 135-153.

Vilches de Frutos, Francisca (2010b). «El exilio a través de los mitos: La libertad en el tejado, de María Teresa León», en Antonio Fernández Insuela, María del Carmen Alfonso García, María Martínez-Cachero Rojo y Miguel Ramos Corrada (coord.), Setenta años después. El Exilio Literario español de 1939. Oviedo: KRK, pp. 689-708.

Vilches de Frutos, Francisca (2010c). «Representaciones de género en el teatro español contemporáneo. La igualdad en la construcción del espacio cultural europeo», Aleph. 24, pp. 9-28.

Zatlin, Phyllis (1995). «El teatro de Ana Diosdado: ¿conformista?», en Alfonso del Toro y Wilfried Floeck (ed.), Teatro español contemporáneo: autores y tendencias. Kassel: Reichenberger, pp. 125-149.

Zatlin, Phyllis (2006). «Traditional Sex Roles in the Theatre of Ana Diosdado», Letras femeninas. 32: 1, pp. 119-128.

Zaza, Wendy-Llyn (2007). Mujer, historia y sociedad: La dramaturgia española contemporánea de autoría femenina. Kassel: Reichenberger.

Fecha de recepción: 19 de julio de 2014.

Fecha de aceptación: 11 de febrero de 2015.

Revista de Literatura, 2016, vol. LXXVIII, n. ${ }^{\circ}$ 156, 499-523, ISSN: 0034-849X, doi: 10.3989/revliteratura.2016.02.021 